\title{
Supernumerary Teeth from Two Mesoamerican Archaeological Contexts
}

\author{
William N. Duncan* \\ Department of Anthropology, St. John Fisher College, Rochester, NY
}

\begin{abstract}
Supernumerary teeth are uncommon but have been well documented clinically. The majority of cases are isolated anterior teeth; examples of multiple or posterior supernumerary teeth are less common. This paper describes two examples of supernumerary teeth from archaeological contexts in Mesoamerica. The first case is of three individuals with supernumerary posterior teeth found in skull rows and pairs in a Postclassic Maya temple at the site of Ixlú in northern
\end{abstract}

Case studies of supernumerary teeth have been recorded clinically at least since the Paul of Aegina discussed their treatment in the 7th century among the Greeks, the 10th century in Persia, and the 18th century in France and Germany (Guerini, 1909). Although a rare trait, constituting a deviation in normal dental development, case studies of isolated supernumerary teeth are not uncommon in the clinical literature from around the world (Garvey et al., 1999; Orhan et al., 2006; Rajab and Hamdan, 2002; Scheiner and Sampson, 1997; Solares and Romero, 2004; see Yusof, 1990; Zhu et al., 1996 for review articles). Case studies have also been reported in archaeological (Alt, 1990) and paleontological contexts reaching back to earlier hominids (Ripamonti et al., 1999). Finding examples of nonsyndromic multiple supernumerary teeth is rarer however. In this paper I review what is known about frequency, nosology, location, ontogeny, function, and mode of inheritance of supernumerary teeth and describe cases from two archaeological contexts in Mesoamerica. The first context is a Postclassic Maya temple at the site of Ixlú in northern Guatemala in which there were 21 skulls arranged in rows and pairs. Three of these individuals had supernumerary mandibular teeth and 2 individuals exhibited them bilaterally. The second context is from Oaxaca, Mexico. An individual had one supernumerary tooth that was unerupted but visible due to broken mandible. I conclude the paper by discussing the cases' relevance to biological distance analyses.

\section{BACKGROUND}

Supernumerary teeth are typically classified with reference to number of teeth, morphology (Kalra et al., 2005), and location. The number of teeth is clinically meaningful because multiple supernumerary teeth are
Guatemala. Two of these individuals exhibited bilateral supernumerary mandibular teeth. The second context is a Zapotec burial from the Jalieza site in Oaxaca, Mexico. This individual exhibited a single supernumerary tooth. The paper reviews supernumerary teeth with regard to frequency, ontogeny, and mode of inheritance and discusses the cases' relevance for biological distance analyses. Dental Anthropology 2009;22(2):39-46.

typically syndromic (Fernández Montenegro et al., 2006; Garvey et al., 1999) and because increased numbers of teeth are more likely to require intervention (Högström and Andersson, 1987). Fernández Montenegro et al. (2006) classify morphology as eumorphic (retaining the normal features of a member of the tooth field in which they develop) and heteromorphic. They divide heteromorphic teeth into conical, tuberculate, molariform, and infundibular. Garvey et al. (1999) divide morphology into conical, tuberculate (having multiple cusps, which includes invaginated or barrel shaped teeth), supplemental (eumorphic), and odontome (further classified as either complex or compound). The last category, odontomes, is not universally agreed upon as a supernumerary tooth class (De Oliveira Gomes, 2008; Garvey et al., 1999). In addition to normal tooth fields, location is frequently categorized as mesiodens, distomolars, or paramolars (Fernández Montenegro, 2006). However, some teeth that are inverted can also be classified as nasal (Alt, 1990; Hiranandani and Melgiri, 1968).

Assessments of population percentages exhibiting supernumerary are fairly consistent in the literature and range from $0.1-3.6 \%$ when including all teeth (Brook, 1974; Liu, 1995; Hopcraft, 1998; Scheiner and Sampson, 1997; see Luten, 1967 for review of earlier studies). Separating permanent and deciduous teeth suggests that the phenomenon is more common in the former $(0.5-3.8 \%)$ than the latter $(0.3-0.6 \%$; Fernández

\footnotetext{
${ }^{*}$ Correspondence to: William N. Duncan, Department of Anthropology, St. John Fisher College, 3690 East

Avenue, Rochester, NY 14620

E-mail: bduncan@sjfc.edu
} 
Montenegro et al., 2006; Scheiner and Sampson, 1997). The majority of these cases are single teeth $(77-86 \%$; Orhan et al., 2006; Scheiner and Sampson, 1997; Rajab and Hamdan, 2002). Cases of multiple supernumerary teeth are less common and most often associated with syndromes, such as Gardner syndrome, or cleft lip and palate, or cleidocranial dysplasia. Orhan and colleagues (2006) note that over 20 conditions have been associated with supernumerary teeth.

Nonsyndromic cases of supernumerary teeth (hyperdontia) have been reported occasionally in the literature as well, though they are rarer (Bayar et al., 2008; Desai and Shah, 2007; Gündüz and Muğlali, 2007; Kalra et al., 2005; King, 1993; Leite et al., 2007; Leslie, 1984; Moore et al., 2002; Manrique Morá et al., 2004; Mopager et al. 2002; Rosenthaler and Beideman, 1983; Ruhlman and Neely, 1964; Orhan et al., 2006; Refoua and Arshad, 2006; Sasaki et al., 2007; Sharma, 2001; Yusof and Awang, 1990; Yusof, 1990; Zhu et al., 1996; see references therein for earlier case studies and Açikgöz et al., 2006 in particular for review). It should be noted that some researchers quantify supernumerary teeth as single teeth, doubles, or multiples, but count the latter category as having more than 5 extra teeth (e.g., Arathi and Ashwini, 2005; Scheiner and Sampson, 1997), although it is unclear if this classification has any etiological basis. The highest number of nonsyndromic supernumerary teeth I have seen in the literature is 22, in a 10-year-old male (Rizzuti and Scotti, 1997). Açikgöz et al. (2006) found a frequency of $0.06 \%$ of all cases of supernumerary teeth exhibited multiple teeth in a retrospective study. De Oliveira Gomes et al. (2008) found 37\% of individuals with supernumerary teeth had more than 1 , but only $2 \%$ had 5 or more.

Males are more affected by supernumerary teeth than females, and the reverse is true for congenital absence of teeth (Brook, 1974). Rajab and Hamdan (2002) report a male to female ratio of 2.2:1. Similar numbers were found by other studies (Mason et al., 2002; Mitchell, 1989), but higher and lower estimates exist. Davis (1987) found a ratio of 6.5 males to every female in a sample of 1,093 Hong Kong school children $(2.74 \%$ with a $95 \%$ confidence interval of $\pm .9604 \%$ ). Brook (1974) however found a male to female ratio of 1:0.7 among 1,115 white British school children $(2.1 \%$ with a $95 \%$ confidence interval of $\pm 0.83 \%)$. Given the overlapping confidence intervals in the estimates, the difference in sex ratio may be due to variation between populations or sampling fluctuation. There is some variability reported regarding the overall frequency of supernumerary teeth among populations. Brown (1990) and Zhu et al. (1996) report that Subsaharan African and Asian populations exhibit somewhat higher prevalence (between 2.7\% and 3.4\%) than that found in Brook (1974) and Luten (1967). That said, the relative population frequencies among the different categories and locations of supernumerary teeth are still unknown, so accurately characterizing interpopulation variability remains difficult.

Some studies report the most common supernumerary teeth are mesiodens (see Garvey et al., 1999; Refoua and Arshad, 2006), which may reflect a high representation of European data in the literature because variation exists. Luten (1967) found the most common locations (in decreasing order) to be upper lateral incisors, mesiodens, upper central incisors, and premolars when both permanent and deciduous dentitions were combined. Orhan et al. (2006:891-892) note that the most common supernumerary teeth are mesiodens, followed in descending frequency by "maxillary fourth molars, maxillary paramolars, mandibular premolars, maxillary lateral incisors, mandibular fourth molars, and maxillary premolars." Also, Fernández Montenegro et al. (2006) found lateral incisors and canines to be rare relative to other, distal positions. Thus, while most studies find increased frequency in maxillary and anterior position, there is variability. There does seem to be agreement that when multiple nonyndromic supernumerary teeth are present, they are most often premolars (Açikgöz et al., 2006; Solares and Romero, 2004).

As noted, multiple supernumerary teeth frequently are associated with syndromes. The actual mechanism resulting in supernumerary teeth is often attributed to independent, hyperactivity of the dental lamina in a localized context (Solares and Romero, 2004). Another explanation is that after supernumerary teeth could emerge from a dichotomized tooth bud (Brook, 1984; Leite, 2007; Moore et al. ,2002; see D'Souza and Klein, 2007 for review). A third, but less cited explanation is an atavistic origin (Hattab et al., 1994; Marya and Kumar, 1998). Development of supernumerary teeth can happen at different times in life. Järvinen (1976) documented a case in which supernumerary teeth were extracted in a child and later X-rays disclosed that more supernumerary teeth had developed. What does seem clear is that although there may be some non-genetic or epigenetic involvement (Suda et al., 2007), there is a genetic component (Batra et al., 2005; Becker et al., 1982; Desai and Shah, 2007; Langowska-Adamcyżk and Karmaňska, 2001; Marya and Kumar, 1998; Mercuri and O'Neill, 1980; Umweni and Osunbor, 2002) and it does not appear to be the result of simple Mendelian inheritance (Yusof, 1990). Studies have suggested that transmission of supernumerary teeth may be autosomal dominant (Batra et al., 2005) or sex linked (Hattab et al., 1994), the latter scenario might account for the higher frequencies in males.

\section{Case 1 - Ixlú}

At the Maya site of Ixlú, in northern Guatemala, 21 skulls were found in pairs and rows in a Postclassic temple (Structure 2023; Fig. 1). The skulls were visually examined and were not radiographed. Three of these 


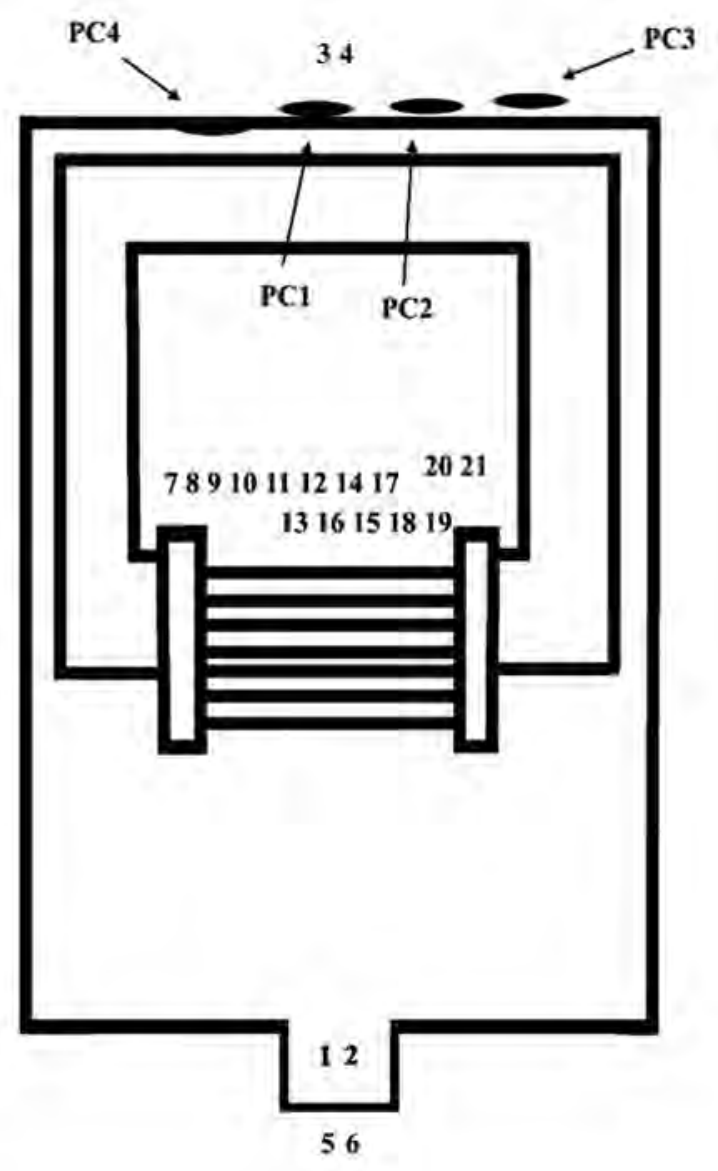

Fig. 1. Position of skulls in pairs and rows at Structure 2023 in Ixlú, Guatemala. Locations are denoted by positions of the numbers, 1 through 21. PC stands for postcranial remains.

individuals exhibited supernumerary teeth (skulls 1,7 , and 16). All of these teeth were erupted with the exception of the left side supernumerary tooth on individual 1 (see below). Six skulls had been placed in pairs on the midline on the east and west sides of the building (skulls 1, 2, 3, 4, 5, and 6) in a late construction stage. Postcranial remains of 4 individuals were placed on top of this floor as well on the west side of the building perpendicular to the skull pairs. The postcrania lacked hand, foot, or cranial elements and exhibited cutmarks at the joints of the long bones. The long bones were placed on top of the axial skeletons in bone bundles (Duncan, 2005). The other skulls were placed in rows above the skull pairs, above a lower floor in the center of the building. It should be noted that there were two episodes of deposition and that skulls 1 and 2 appear to have been interred at the same time as the skull row (Duncan, 2005). Skulls 3, 4, 5, and 6 likely correspond to the four postcrania found behind the temple, though individuation proved impossible. All of the skulls were seated on the floors and faced east except for those clearly overturned by root action. All skulls except for 2, 10, 11, 15,18 had articulated cervical vertebrae underneath them. It should be noted that skulls 10 and 11 were only represented by fragments of cortical bone and could not be identified as separate skulls osteologically in laboratory analysis. However, they intersected a looter's trench, and it is parsimonious to include them in the final count of 21. It is likely that other skulls were also part of the rows and were originally located to the south of skull 13 prior to looting (Fig. 1). Sex was assessed by the use of standard anthroposcopic features described in Buikstra and Ubelaker (1994), with the omission of the mastoid process, which may be artificially hypertrophied in this culture area due to tumpline use. Three of the skulls in pairs and 8 of the skulls in rows could be assessed for sex, all of which were male (including skulls 1 and 7). Poor preservation precluded using cranial suture closure to assess age, but all of the skulls that could be observed were either late adolescent to adult in age on the basis of dental eruption. Markers that may have been used to distinguish young versus older adulthood (the sphenoccipital synchondrosis and the palate sutures) were not observable. Two of the skulls (2 and 5) exhibited frontooccipital cranial modification and skull 13 exhibited dental modification (Romero [1970] III-6 Style).

Skull 1, an adult male, exhibited bilateral supernumerary mandibular teeth. On the left side, the tooth was found between P4 and M1 and was lingual to the tooth row (Fig. 2). The tooth was tuberculate with a dominant buccal cusp and a weak lingual cusp. A small accessory mesial cusp was visible as well (Fig. 3). No occlusal wear was visible on the tooth, and it would not have been in contact with maxillary teeth. The alveolar bone was broken around this tooth, but it may not have been emerged in life. There is no evidence that it displaced

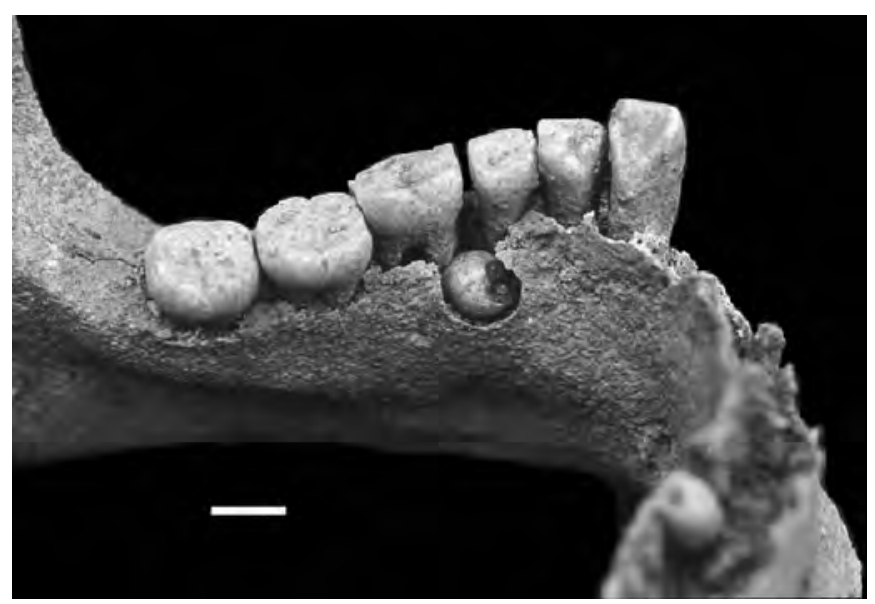

Fig. 2. Supernumerary teeth in skull 1, Ixlú, Guatemala. There is an extra premolar lingual to the distal premolar on the specimen's left side. Note that there also is a extra, conical tooth on right side of the jaw. 


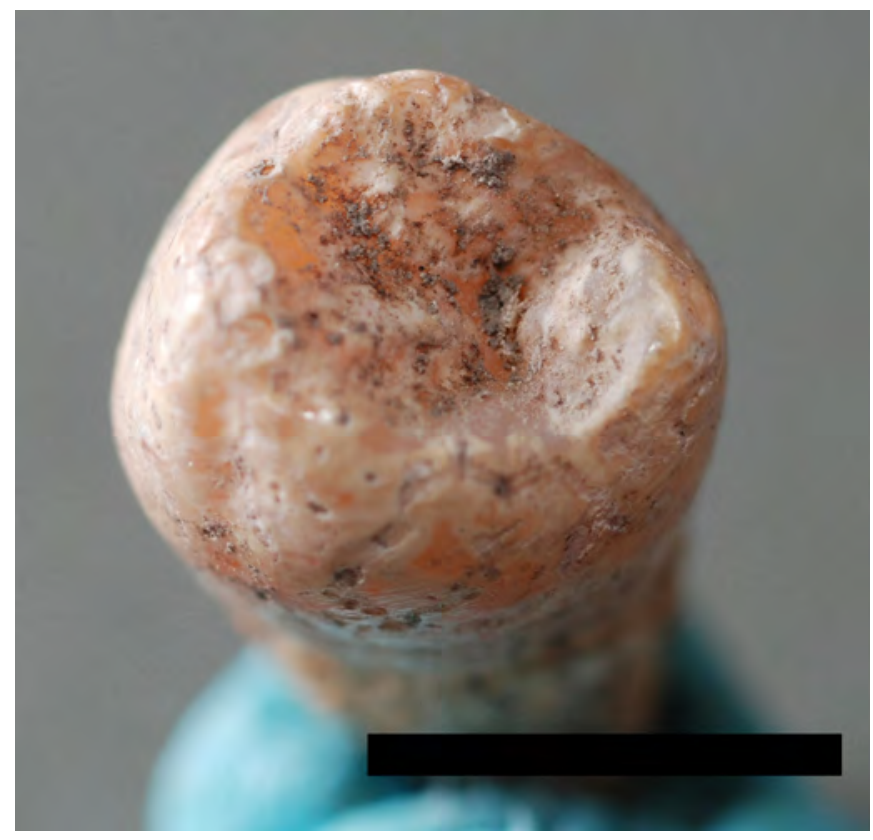

Fig. 3. Supernumerary tooth on left side from skull 1, Ixlú, Guatemala. Occlusal view from the buccal side. Scale $5 \mathrm{~mm}$. Photo courtesy David Long.

other teeth. The root appears to be incisiform, and no radicals were visible. The right side supernumerary tooth was between the canine and P3 and was also lingual to the tooth row (Fig. 2). It was conical with slight lingual invagination and had no occlusal wear. The tooth root was broken near the cementoenamel junction. Poor preservation precluded assessing if the adjacent teeth would have been displaced. There is no evidence that other teeth were altered in size.

Skull 7, an adult of unknown sex, exhibited bilateral supernumerary mandibular teeth. The left supernumerary tooth was lingual to P3, displacing it buccally (Fig. 4). The supernumerary tooth was molariform, exhibiting 5 cusps and had a talonid. It was in occlusion and the roots could not be observed. No wear was present, and it would not have made contact with maxillary teeth unless other teeth had worn down considerably more. The right supernumerary tooth was between P3 and P4, though mesial to the tooth row (Fig. 5). It was tuberculate, exhibiting a single primary cusp and an accessory distal cusp. The tooth was not well preserved and the apex of the root was broken. It was not in occlusion and it is unclear if it would have displaced other teeth. There is no evidence that other teeth were altered in size.

Skull 16, a late adolescent to adult of unknown sex, exhibited a single supernumerary mandibular tooth (Fig. 6). The tooth was mesial to the other premolars and between P3 and P4 on the right side. The tooth was tuberculate with a dominant buccal cusp and 2 lingual cusps of roughly equal size. The buccal side exhibited

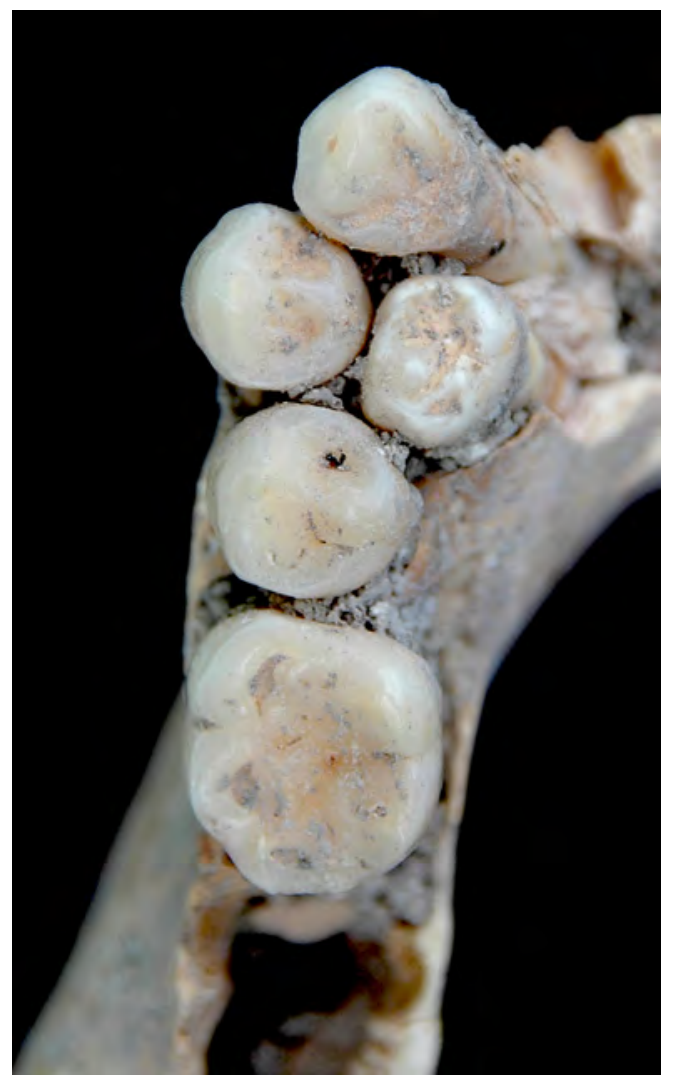

Fig. 4. Supernumerary tooth on left side from skull 7, Ixlú, Guatemala.

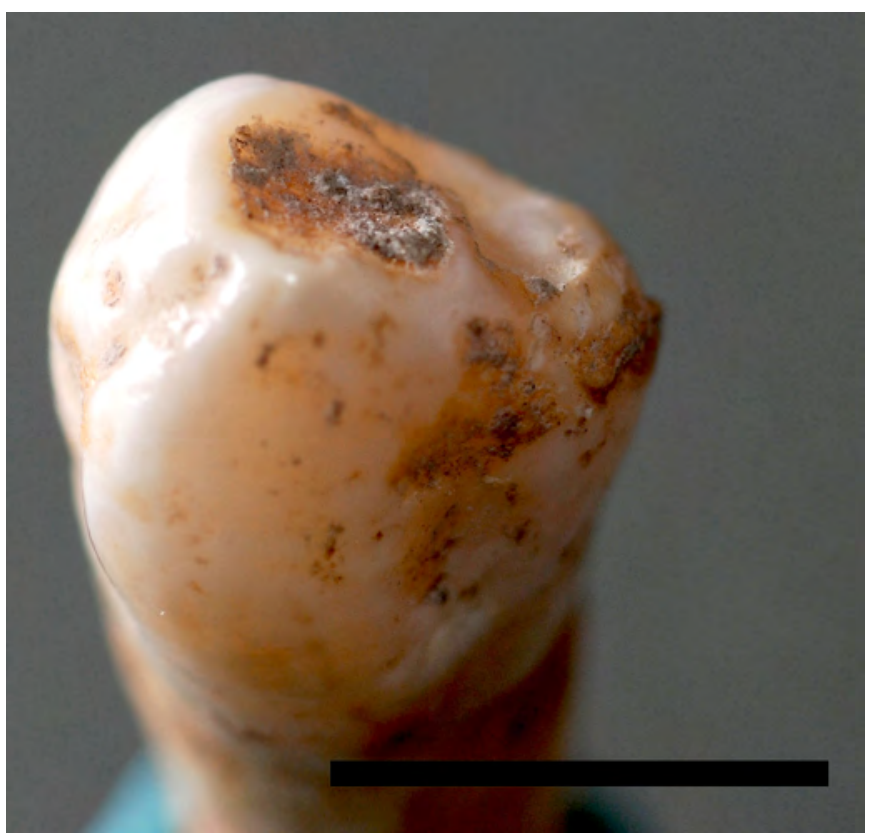

Fig. 5. Supernumerary tooth on right side from skull 7, Ixlú, Guatemala. Occlusal surface from lingual view. Distal cusp is on the right. Scale $5 \mathrm{~mm}$. Photo courtesy of David Long. 


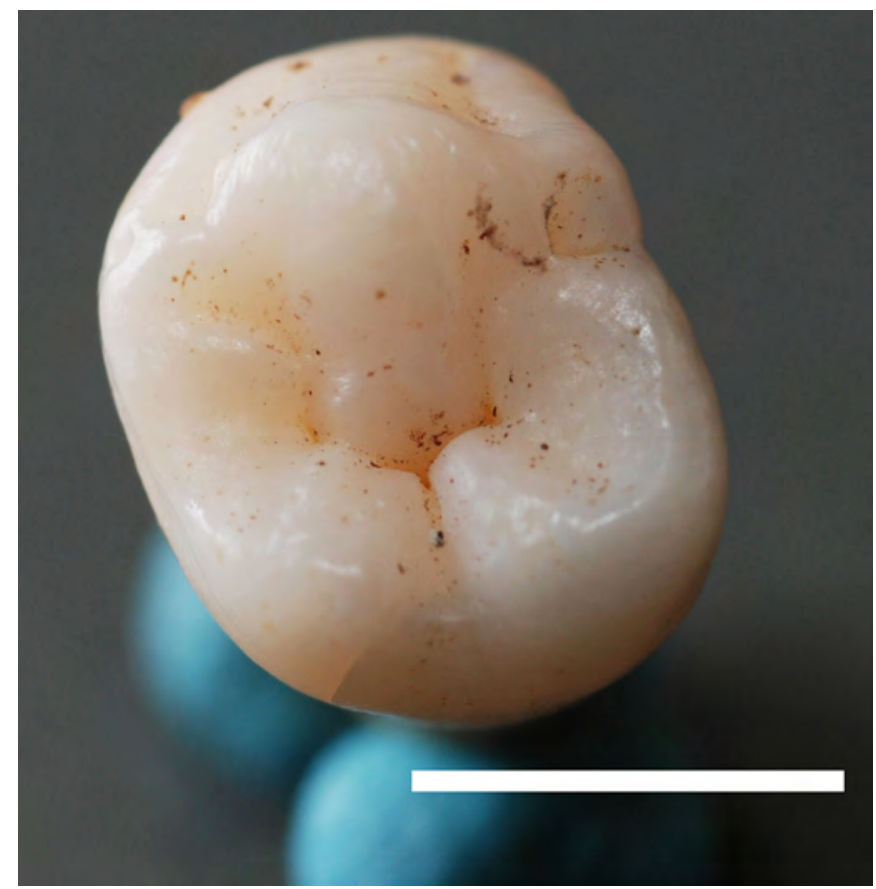

Fig. 6. Supernumerary tooth from skull 16, Ixlú, Guatemala. Scale is $5 \mathrm{~mm}$. Photo courtesy of David Long.

2 grooves on it. The tooth was not in occlusion and no wear was evident. The root was longer buccolingually than mesiodistally and exhibited no radicals. The apex of the root was not closed. Preservation precluded observing whether or not other teeth were displaced because of the supernumerary tooth, though it is likely that it did given its size and locarion. The third molars were bilaterally somewhat smaller than the other teeth, though it is unclear if this stems from the supernumerary tooth.

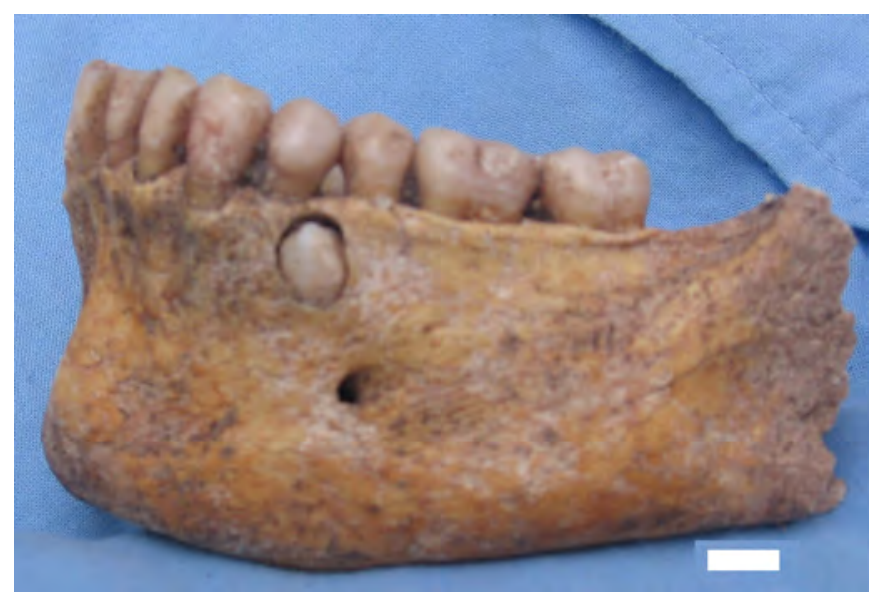

Fig. 7. Supernumerary tooth from individual at Jalieza, Oaxaca, Mexico. This tooth (unerupted) is visible in the alveolus because it has resorbed the buccal aspect of the bone adjacent to it. Its position is between the roots of the two erupted premolars. Scale $5 \mathrm{~mm}$.

\section{Case 2 - Jalieza}

The second context that yielded a supernumerary tooth was a Late Classic period burial from the Zapotec site of Jalieza in the Oaxaca valley. The individual was an adult male. The supernumerary tooth was unerupted and was only visible because the surrounding alveolar bone was broken. The dentition was visually assessed and was not confirmed with an X-ray. The tooth was visible on the left buccal side of the mandible and was between P3 and P4 (Fig. 7). It was superior and mesial to the mental foramen. Neither the crown nor root morphology was visible. There was no evidence of displacement of any of the teeth but the third molar on the left side was absent (Fig. 8).

\section{DISCUSSION}

The Ixlú case stands out primarily because of the likelihood of finding three individuals in such a small sample with supernumerary teeth is so low. There have been no studies on the frequency of supernumerary teeth in Mesoamerican populations, but two Maya biodistance studies have found them. Jacobi (2000) found 3 cases of supernumerary teeth at Tipu out of over 500 burials. Two were single teeth and 1 individual had 2 supernumerary teeth. All were maxillary. Lang (1990) found a total of 13 supernumerary teeth in her study at Lamanai out of 89 individuals. Six of these were maxillary and resemble Jacobi's description. However, 7 were mandibular and resemble what I found at Ixlú, based on Lang's (1990) description. In a clinical context Hopcraft (1998) found that 1.6 to 3.1\% of people have supernumerary teeth but only 3 to

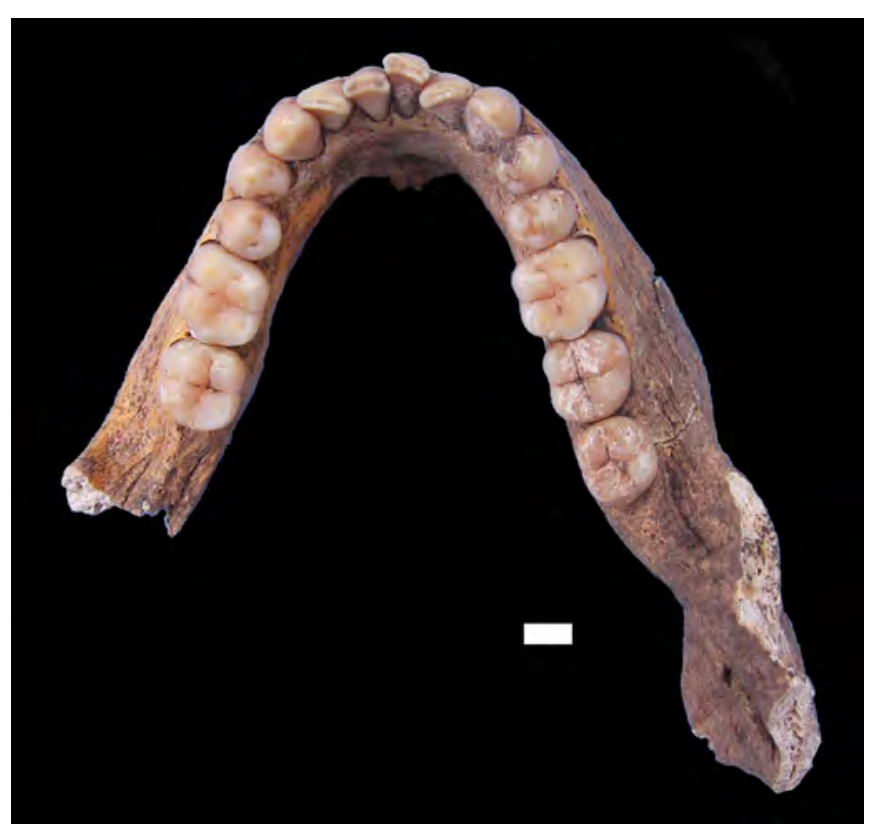

Fig. 8. Absence of left mandibular third molar from individual at Jalieza, Oaxaca, Mexico. Scale $5 \mathrm{~mm}$. 
$10.9 \%$ of supernumerary teeth are in the premolar field, a range consistent with aforementioned citations. If one accepts the interval of 1.6 to $3.1 \%$ as the range of frequencies for some manifestation of supernumerary teeth (and there is no current evidence to think it is more common among the Maya than that) the average is $2.35 \%$, and the average of $3 \%$ and $10.9 \%$ is $6.95 \%$. $6.95 \%$ of $2.35 \%$ is $0.16 \%$ or a 1 in 625 chance of having this trait. I used the resampling software (and modified the "birthday program"; Simon, 1990) to estimate the likelihood of finding 3 of 17 individuals having mandibular supernumerary teeth with this frequency. Only 17 individuals were observable for the trait. If the likelihood of finding mandibular supernumerary teeth is 1 in 625 , then one can randomly select 17 numbers from 625 . This was repeated 10,000 times, out of which 17 times or $0.2 \%$ that the same number came up 3 times, which is statistically significant and suggests that the individuals were likely related, although at what level remains unclear.

The two cases described here also highlight three potential problems with using supernumerary traits in biodistance analyses. The first problem, highlighted by the Jalieza case, is that many supernumerary teeth are subclinical in life and invisible in death because they do not emerge so including them in such analyses may actually obscure relationships. This is consistent with Açikgöz et al. (2006) who found 30 of 37 supernumerary teeth they studied to be impacted. Certainly such traits have utility, but are other people in the skull rows and pairs who have supernumerary traits just not being counted? The second problem, also highlighted by the Jalieza case, is that there may be interactions between tooth fields. The congenital absence of the third molar on the same side may or may not be due to the supernumerary tooth, but accounting for the correlation if you are using both as separate traits is necessary. This may mimic examples in which supernumerary teeth were found in conjunction with atypical morphodifferentiation (Manrique Morá et al., 2004). Finally, the Ixlú cases suggest that supernumerary teeth likely should be scored as present or absent in biodistance analyses. The fact that the left supernumerary tooth is highly molariform and the right is much simpler in skull 7 at Ixlú may suggest that influences reflect environmental influence. Similar heterogeneity has been found in individuals with many more supernumerary teeth as well (So, 1990). This could be true whether they are attributable to the splitting of the tooth bud or localized or independent activity of the lamina.

\section{ACKNOWLEDGEMENTS}

I would like to thank Dr. Rob Corruccini for his input on this and related projects over the last 10 years (dental and otherwise). The remains from Ixlú were excavated under the auspices of Proyecto Maya Colonial directed by Drs. Prudence M. Rice, Don S. Rice, and Lic. Romulo Sanchez Polo, whom I would also like to thank. Figure 1 was originally drawn in the field by Lic. Ivo Romero. David Long kindly made the photographs used in Figures 3, 5, and 6. The excavations in Guatemala were completed with permission from IDAEH and able assistance from its inspectors Lic. Boris Aguilar and Sheila Flores. In Mexico, the remains were excavated as a part of the Jalieza Project with Drs. Christina Elson and Luca Casparis, with whom I am grateful to work, and with kind permission from INAH. Funding for this project was given in part by the National Science Foundation (BCS \#0125311), the American Museum of Natural History, National Geographic, and St. John Fisher College. All errors remain my own.

\section{LITERATURE CITED}

Açikgöz A, Açikgöz G, Tunga U, Otan F. 2006. Characteristics and prevalence of non-syndrome multiple supernumerary teeth: a retrospective study. Dentomaxillofac Radiol 35:185-190.

Alt K. 1990. Nasal teeth: report of a historic case. Int J Anthropol 5:245-249.

Arathi R, Ashwini R. 2005. Supernumerary teeth: a case report. J Indian Soc Pedod Prev Dent 23:103-105.

Bayar GR Ortakoglu K, Sencimen M. 2008. Multiple impacted teeth: report of 3 cases. Eur J Dent 2:73-78.

Batra P, Duggal R, Parkash H. 2005. Non-syndromic multiple supernumerary teeth transmitted as an autosomal dominant trait. J Oral Pathol Med 34:621625.

Becker A, Bimstein E, Shteyer A. 1982. Interdisciplinary treatment of multiple unerupted supernumerary teeth: report of a case. Am J Orthod 81:417-422.

Brook A. 1984. A unifying aetiological explanation for anomalies of human tooth number and size. Arch Oral Biol 29:373-378.

Brook A. 1974. Dental anomalies of number, form and size: their prevalence in British schoolchildren. J Int Assoc Dent Child 5:37-53.

Brown A. 1990. Supplemental and congenitally absent premolar teeth. Br Dent J 169:150.

Buikstra J, DH Ubelaker. 1994. Standards for data collection from human skeletal remains. Fayetteville, AR: Arkansas Archaeological Survey.

D'Souza R, Klein OD. 2007. Unraveling the molecular mechanisms that lead to supernumerary teeth in mice and men: current concepts and novel approaches. Cells Tissues Organs 186:60-69.

Davis PJ. 1987. Hypodontia and hyperdontia of permanent teeth in Hong Kong schoolchildren. Community Dent Oral Epidemiol 15:218-220.

De Oliveira Gomes C, Neves Drummond S, Correia Jham B, Neves Abdo E, Alves Mesquita R. 2008. A survey of 460 supernumerary teeth in Brazilian chil- 
dren and adolescents. Int J Paediatr Dent 18:98-106.

Desai RS, Shah NP. 2007. Multiple supernumerary teeth in two brothers: a case report. J Oral Pathol Med 27:411-413.

Duncan WN. 2005. The bioarchaeology of ritual violence in Postclassic El Petén, Guatemala (AD 950-1524). PhD Dissertation, Carbondale, IL: Southern Illinois University Carbondale.

Fernández Montenegro P, Valmaseda Castellón E, Berini Aytés L, Gay Escoda C. 2006. Retrospective study of 145 supernumerary teeth. Med Oral Patol Oral Cir Bucal 11:339-344.

Garvey M, Barry HJ, Blake M. 1999. Supernumerary teeth: an overview of classification, diagnosis and management. J Can Dent Assoc 65:612-616.

Guerini V. 1909. A history of dentistry from the most ancient times until the end of the eighteenth century. New York: Lea and Febiger.

Gündüz K, Muğlali M. 2007. Non-syndrome multiple supernumerary teeth: a case report. J Contemp Dent Pract 8:81-87.

Hattab F, Yassin OM, Rawashdeh MA. 1994. Supernumerary teeth: report of three cases and review of the literature. ASDC J Dent Child 61:382-393.

Hiranandani L, Melgiri RD. 1968. Supernumerary tooth in the floor of the nose. J Laryngol Otol 82:845-848.

Högström A, Andersson L. 1987. Complications related to surgical removal of anterior supernumerary teeth in children. ASDC J Dent Child 54:341-343.

Hopcraft M. 1998. Multiple supernumerary teeth: case report. Aust Dent J 4:17-19.

Jacobi K. 2000. Last rites for the Tipu Maya: Genetic structuring in a colonial cemetery. Tuscaloosa: University of Alabama Press.

Järvinen S. 1976. Formation of multiple supernumerary teeth in early teenage: a case report. Proc Finn Dent Soc 72:132-134.

Kalra N, Chaudhary S, Sanghi S. 2005. Non-syndrome multiple supplemental supernumerary teeth. J Indian Soc Pedod Prev Dent 23:46-48.

King N. 1993. Multiple supernumerary premolars; their occurrence in three patients. Aust Dent J 38:11-16.

Lang C. 1990. The dental morphology of the ancient Maya from Lamanai and Tipu, Belize, a study of population movement. MA Thesis, Department of Anthropology: Trent University.

Langowska-Adamczyk H, Karmaňska B. 2001. Similar locations of impacted and supernumerary teeth in monozygotic twins: a report of 2 cases. Am J Orthod Dentofacial Orthop 119:67-70.

Leite A, Suginski-Barbosa J, Faleiros FB, Chagas EA. 2007. Nonsyndromic supernumerary teeth: case report. Dent Today 26:140-143.

Leslie JC. 1984. Multiple supernumerary teeth. Oral Surg Oral Med Oral Pathol 57:463.

Liu J. 1995. Characteristics of premaxillary supernu- merary teeth: a survey of 112 cases. ASDC J Dent Child 62:262-265.

Luten JJ. 1967. The prevalence of supernumerary teeth in primary and mixed dentitions. J Dent Child 34:346353.

Manrique Morá M, Bolaños Carmona MV, Briones Luján MT. 2004. Molarization and development of supernumerary teeth in the premolar region. J Dent Child 71:171-174.

Marya C, Kumar BR. 1998. Familial occurence of mesiodentes with unusual findings: case reports. Quintessence Int 29:49-51.

Mason C M, Azam N, Holt RD, Rule DC. 2000. A retrospective study of unerupted maxillary incisors associated with supernumerary teeth. Br J Oral Maxillofac Surg 38:62-65.

Mercuri L, O'Neill R. 1980. Multiple impacted and supernumerary teeth in sisters. Oral Surg Oral Med Oral Pathol 50:293.

Mitchell L. 1989. Supernumerary teeth. Dent Update 16:65-69.

Moore S, Wilson DF, Kibble J. 2002. Sequential development of multiple supernumerary teeth in the mandibular premolar region-a radiographic case report. Int J Paediatr Dent 12:143-145.

Mopager V, Suda SP, Anegundi RT, Kulkarni S, Tavarageri A. 2002. Supplemental premolars in a 13 year old child: a case report. J Jndian Soc Pedo Prev Dent 20:169-172.

Orhan A, Ozer L, Orhan K. 2006. Familial occurrence of nonsyndromal multiple supernumerary teeth: a rare condition. Angle Orthod 76:891-897.

Rajab L, Hamdan, MA. 2002. Supernumerary teeth: review of the literature and a survey of 152 cases. Int J Paediatr Dent 12:244-254.

Refoua Y, Arshad M. 2006. An unusual case of bilateral maxillary and mandibular supernumerary teeth. J Dent Tehran U Med Sci 3:140-142.

Ripamonti U, Petit JC, Thackeray JF. 1999. A supernumerary tooth in a 1.7 million-year-old Australopithecus robustus from Swartkrans, South Africa. Eur J Oral Sci 107:317-321.

Rizzuti N, Scotti S. 1997. A case of hyperodontia with twenty-two supernumeraries: its surgical-orthodontic treatment. Am J Orthod Dentofacial Orthop 111:471-480.

Romero J. 1970. Dental mutilation, trephination, and cranial deformation. In: Stewart T, editor. Physical Anthropology. Handbook of Middle American Indians. Vol. 9. Austin: University of Texas. p 50-67.

Rosenthaler H, Beideman RW. 1983. Multiple supernumerary teeth. Oral Surg Oral Med Oral Pathol 56:227.

Rhulman D, Neely AR. 1964. Multiple impacted and erupted supernumerary teeth: report of a case. Oral Surg Oral Med Oral Pathol 17:199-203.

Sasaki H, Funao J, Morinaga H, Nakano K, Ooshima,T. 
2007. Multiple supernumerary teeth in the maxillary canine and mandibular premolar regions: a case in the postpermanent dentition. Int J Paediatr Dent 17:304-308.

Scheiner M, Sampson WJ. 1997. Supernumerary teeth: a review of the literature and four case reports. Aust Dent J 42:160-165.

Sharma A. 2001. A rare non-syndrome case of concomitant multiple supernumerary teeth and partial anodontia. J Clin Pediatr Dent 26:167-169.

Simon J. 1990. Resampling stats. Arlington, VA: Resampling Stats, Inc.

So LL. 1990. Unusual supernumerary teeth. Angle Orthod 60:289-292.

Solares R, Romero MI. 2004. Supernumerary premolars: a literature review. Pediatr Dent 26:450-458.
Suda N, Hamada T, Hattori M, Torii C, Kosaki K, Moriyama K. 2007. Diversity of supernumerary tooth formation in siblings with cleidocranial dysplasia having identical mutation in RUNX2 : possible involvement of non-genetic or epigenetic regulation. Orthod Craniofac Res 10:222-225.

Umweni A, Osunbor GE. 2002. Non-syndrome multiple supernumerary teeth in Nigerians. Odontostomatol Trop 25:43-48.

Yusof W. 1990. Non-syndrome multiple supernumerary teeth: literature review. J Can Dent Assoc 56:147-149.

Yusof W, Awang MN. 1990. Multiple impacted supernumerary teeth. Oral Surg Oral Med Oral Pathol 70:126.

Zhu J, Marcushamer M, King DL, Henry RJ. 1996 Supernumerary and congenitally absent teeth: a literature review. J Clin Pediatr Dent 20:87-95. 